In press / forthcoming in Demography

\title{
Research Note: School Reopenings During the COVID-19 Pandemic and Implications for Gender and Racial Equity ${ }^{1}$
}

\author{
Liana Christin Landivar \\ Women's Bureau, U.S. Department of Labor ${ }^{2}$ \\ Maryland Population Research Center \\ https://orcid.org/ \\ 0000-0001-5141-9344 \\ Leah Ruppanner \\ University of Melbourne \\ https://orcid.org/ \\ 0000-0002-6111-1914 \\ Lloyd Rouse \\ University of Melbourne \\ William J. Scarborough \\ University of North Texas \\ https://orcid.org/ \\ 0000-0002-1566-4921 \\ Caitlyn Collins \\ Washington University in St. Louis \\ https://orcid.org/ \\ 0000-0002-9358-8151
}

\footnotetext{
${ }^{1}$ Funding for this project comes from the Russell Sage Foundation Presidential Grant R-2007-26580, the Faculty of Arts at the University of Melbourne, and the Weidenbaum Center on the Economy, Government, and Public Policy at Washington University in St. Louis.

${ }^{2}$ Views presented are those of the authors and not necessarily those of the U.S. Department of Labor.
} 


\title{
RESEARCH NOTE
}

\section{Research Note: School Reopenings During the COVID-19 Pandemic and Implications for Gender and Racial Equity}

\begin{abstract}
In the fall of 2020, school districts across the country reopened under varied instructional modes. Some school districts returned to in-person instruction; some operated remotely. Others reopened under hybrid models, wherein students alternated times, days, or weeks of in-person instruction. To capture this variation, we developed the Elementary School Operating Status (ESOS) database. ESOS provides data on elementary school districts' primary operating status in the first grading period of the 2020-2021 school year, covering 24 million students in over 9,000 school districts in all states. In this research note, we introduce these data and offer two analytical examples. We show that school districts with greater representation of Black and Hispanic students were less likely to offer in-person instruction compared to districts with greater representation of White students. These racial disparities remained after accounting for geographic locale and COVID-19 prevalence. We also show that fewer in-person elementary school instruction days was negatively associated with mothers' labor force participation relative to fathers and women without children. ESOS is a critical data source to evaluate the mid- and long-term implications for students who experienced reduced in-person learning and for mothers who exited employment in the absence of in-person instruction and care.
\end{abstract}




\section{BACKGROUND}

During the COVID-19 pandemic, schools experienced unprecedented closures across all states. Many moved their operations online for extended periods (McElrath 2020), and some school districts did not reopen for in-person instruction in over a year (Thompson 2021). Most states required their school districts to develop continuity of learning plans in the summer of 2020. Yet, school districts across the United States developed very different operating plans, resulting in a patchwork of Kindergarten to $12^{\text {th }}$ grade programming at the start of the 2020-2021 school year. Many school districts reopened in remote status, while others reopened in person. Yet another group of school districts reopened in hybrid status, offering limited attendance to cohorts that alternated times, days, or weeks of in-person instruction. These approaches were a response to a rapidly changing landscape of infection, federal guidance, state and local mandates, teacher union negotiations, and parental surveys (Centers for Disease Control and Prevention 2021). To understand the resulting variation in school reopening, we collected comprehensive data on school districts' reopening status focusing on elementary school students because, in many districts, these plans differed from options offered to older students. Elementary students are of key concern as young students are most likely to require close supervision and assistance to complete remote education (Dorn et al. 2020).

We developed the Elementary School Operating Status (ESOS) database, which provides data on school districts' primary operating status in the first grading period of the 2020-2021 school year. These data are publicly available for 9,195 elementary school districts, representing all 50 states, the District of Columbia, and Puerto Rico (download here: https://osf.io/zeqrj/). Here, we introduce this data source, show the extensive variation in school operating status at the state- and school-district level, and illustrate some of the analytical capabilities of these data. We provide evidence that school districts with greater 
representation of Black and Hispanic students were less likely to offer in-person instruction compared to districts with a greater representation of White students. We also show that fewer in-person elementary school instruction days were negatively associated with maternal employment relative to fathers and women without children.

\section{EDUCATION: FEDERAL, STATE, AND LOCAL OVERSIGHT}

U.S. public schools operate within a complex government legislative structure that leads to heterogeneity across states and local school districts. To access funding, the federal government mandates minimum school day lengths and benchmarks school performance (Lynch 2016). However, federal funding only accounts for 8 cents of each dollar spent on education, with states and local communities providing 83 cents for every dollar spent and 9 cents from private sources (U.S. Department of Education 2018). These stakeholders create a complex public school system that yields disparate funding and educational outcomes across districts (Morgan \& Amerikaner 2018).

With decision-making largely residing at the state or local level, school reopening was determined by state and local governments as one component of broader COVID-19 response plans. At the start of the 2020-2021 school year, California's state government mandated remote learning in counties where cases of COVID-19 remained elevated, and the Oregon governor's directives on school operations were so strict that most schools could not reopen (Cowan 2020; Oregon Health Authority 2020). Many states, such as Illinois and Pennsylvania, allowed for more local discretion in schools' reopening plans, resulting in greater intrastate variation in school operations (Goldstein 2020). On the other hand, the governors of Arkansas and Florida mandated school reopening, resulting in mostly in-person operations at the start of the school year (Demillo 2020; Fraser et al. 2020). 


\section{THE ELEMENTARY SCHOOL OPERATING STATUS DATABASE}

In the absence of federal government plans to collect detailed school district level data on school reopening, we created the Elementary School Operating Status (ESOS) database. ESOS is the most comprehensive database on school district operating status for elementaryaged students. While existing databases on school reopening in fall 2020 provided data for a limited set or the largest school districts, ${ }^{1}$ we cover the majority of school districts: 9,195 of the approximately 13,000 school districts serving all age groups and population sizes. We collect data for districts that serve elementary schools with a minimum of 500 students, which yields coverage for $72 \%$ of all public school districts offering elementary instruction and $98 \%$ of all elementary school students across all 50 states, the District of Columbia, and Puerto Rico. Although $28 \%$ of all districts are not in the ESOS sample, this constitutes only $2 \%$ of elementary school students because districts omitted from ESOS are overwhelmingly rural and with small populations. However, ESOS yields robust coverage of rural areas. The majority of ESOS districts are rural, as there are many more rural districts serving smaller populations of students than urban districts serving large populations. We report differences between districts included in ESOS and those excluded from the sample in the appendix, Table A1.

ESOS data are collected from elementary and unified school districts, focusing on plans for students in grades Kindergarten to grade 6, covering approximately 24 million students. ESOS provides: (1) operating status (in person, hybrid, remote); (2) type of hybrid program (part-day, part-week, alternating weeks); (3) school district population size; (4) estimated number and share of children living in poverty in the school district; (5) number of

\footnotetext{
${ }^{1}$ For example, Education Week tracked 900 out of approximately 13,000 public school districts, Burbio actively monitored 1,200 districts including the largest 200, and MCH Strategic Data had an 18\% response rate to its school operating survey. More recent expansive and laudable efforts use cell phone data to infer school operating status (e.g., U.S. School Closure \& Distance Learning Database), but these collections do not offer the granularity needed to determine which hybrid plans have been implemented and lack precision in determining the share of students allowed to attend under various learning plans.
} 
students by grade; (6) racial and ethnic composition of the school district; and (7) urbancentric locale information. Additional datasets may be linked to ESOS at the state level using state names or codes (e.g., FIPS codes) or National Center for Education Statistics district identifiers at the school district level.

To collect data on the 9,195 districts included in ESOS, we conducted an intensive data collection of materials available in the public domain. School districts must make school reopening plans broadly available to the public so parents and local communities can adjust their plans to schools' operating status. We located the requisite information primarily on school district websites. Many schools also maintain active social media accounts where they provide operational status updates. We also used supplemental sources of information when the reopening plan was ambiguous (e.g., local newspapers) or when state governments or education boards provided the information. All sources have an associated date, which is critical to capture the same period across school districts: operating status as of September 20-30, 2020. We selected this date range because it is the point in the term that covers the majority of the first grading period across most school districts nationwide. If school districts changed status between September 20-30, school districts that began the school year in August were evaluated as of September 20, whereas school districts that began in September were evaluated as of September 30. We developed sampling, data collection, and quality assurance protocols including: (1) all large school districts were verified by at least two team members, including a lead researcher, and; (2) an additional $10 \%$ of the school districts were selected for reverification by a lead researcher to ensure consistent coding (for more details, see ESOS technical documentation: https://osf.io/zeqrj/files/).

School districts were assigned a primary operating status based on the implemented plan for a majority of elementary school grades within the district. We coded schools as operating in person if they offered at least 4 days of in-person instruction per week. Schools 
were classified as remote if no days of in-person instruction were offered for a majority of the student population. Schools operating hybrid plans offered part day (fewer than 4 hours per day), part week (between 1-3 days a week), or rotating week schedules (cohorts attend different weeks). Although schools may operate multiple programs, we classified the district by the most generous in-person option offered to a majority of students. Among schools not already operating primarily in remote status, all school districts offered a remote option, either broadly available to all who requested it or by medical waiver. However, these school districts were only classified as remote if the majority of the grades operated exclusively through remote learning. Data are collected at the school district level. For analytical purposes, we also created a weighted aggregation (by student population size) of school district operating status at the state level (e.g., percent of districts in a state operating in inperson, remote, or hybrid status). The weights ensure that school districts have proportional representation to their student population (see ESOS technical documentation). In addition, we include a categorical classification of states as primarily remote, primarily hybrid, or primarily in-person based on the most common operating status for students in the state.

The aim of this collection is to capture the learning options offered to parents by each school district. This does not capture the extent to which parents opted out of in-person or hybrid options. Learning options offered by school districts are in the public domain and available for all states, whereas parents' choices are not consistently available for most school districts. To capture changes in learning options offered by the school districts during the 2020-21 school year, ESOS will offer a second wave of data with a reference period of April 2021 and future analyses will examine how school districts changed operating plans by the end of the school year. 


\section{SEPTEMBER 2020: SCHOOL OPERATING STATUS}

Figure 1 presents an overview of primary operating status across states. Our data reveal that schools in the West (e.g., California, New Mexico) and along the central eastern seaboard (e.g., Maryland, New Jersey) were predominantly remote. By contrast, six eastern seaboard states operated hybrid models (e.g., New York, Connecticut). Primarily in-person instruction took place in 27 states concentrated in the South and middle of the country. Figure 2 presents this at the school-district level. Many states were homogenous in operations (e.g., California, Maryland, and Oregon) whereas other states had significant variation at the school-district level (e.g., New York, Pennsylvania, and Virginia).

Table 1 reports select district characteristics by reopening status. A slight majority of all districts operated in person (56\%), compared to just under a quarter of districts that operated remotely and a fifth that were hybrid. In-person districts were over twice as likely to be in rural areas than hybrid or remote districts. In-person districts also had student populations that were, on average, one-third the size of remote districts. Therefore, despite most districts adopting in-person instruction, these schools served only $38 \%$ of elementary school students. About $45 \%$ of elementary students attended schools that operated remotely and $17 \%$ of students attended schools with hybrid schedules. Examining differences in the extent of COVID-19 transmission, we find that cases were $15 \%$ higher in remote districts than hybrid districts, and $8 \%$ higher in remote districts than in-person ones. Remote or hybrid schooling policies may have been implemented in response to high local rates of COVID-19 in some districts.

[Table 1 About Here] 


\section{SCHOOL OPERATING STATUS AND RACIAL DISPARITIES}

Table 1 reports differences in schools' racial and ethnic composition by school operating status. We visualize these patterns in Figure 3. Following the definition of Hispanic-Serving Institution by the Department of Education, we classified school districts as having a large Hispanic student population if at least $25 \%$ of students were Hispanic. We classified school districts as having a large Black student population if at least $25 \%$ of students were Black, and as having an overrepresentation of White students if at least $75 \%$ of students were White. Districts that had greater representation of Hispanic and Black students were more likely to be operating remotely. Half of school districts with a large share of Hispanic students were remote, as were $38 \%$ of school districts with a large share of Black students, compared to $11 \%$ of school districts where White students were overrepresented. Only $37 \%$ and $41 \%$ of school districts serving larger percentages of Hispanic and Black students, respectively, were operating in person, compared with $68 \%$ of school districts with predominantly White student populations. Figure 4 shows that these disparities remain across urban, suburban, and rural areas. Appendix Figure A1 also reports consistency in these patterns by local COVID-19 rates. Across locale and COVID-19 conditions, Black- and Hispanic-serving districts were more than twice as likely as predominantly White school districts to be remote.

\section{SCHOOL OPERATING STATUS AND MATERNAL EMPLOYMENT}

Maternal employment in the United States declined significantly during the pandemic and has recovered more slowly than fathers' employment (Landivar et al. 2020; Bauer 2021). Using the Current Population Survey (CPS) (Flood et al. 2020), we assess how school operating status was associated with mothers' labor force participation across all US states. As the CPS lacks adequate sample size to analyze data at the school-district level, we apply 
state-level aggregates. We measure school operating status as the weighted average number of days school districts offer in-person learning. We use CPS data for September-November (years 2019, 2020) to create an adequate sample for state-to-state comparisons. We compare pre-pandemic employment levels in 2019 to employment during the first grading period of the 2020-2021 school year, corresponding to the timeframe in ESOS. We use two counterfactual comparison groups to isolate, as much as possible, the association of school operating status to mothers' labor force participation. First, we compare mothers and fathers aged 18-55 with a youngest child 5-12 years. Labor force attachment for fathers and mothers may be similarly affected by several unobserved state-level characteristics, but because mothers perform the majority of caregiving (Petts et al. 2020), the reduction of in-person schooling should be greater for mothers. Whereas the comparison of fathers and mothers is designed to isolate gendered caregiving allocations, we focus on the association to motherhood by using an additional counterfactual group, comparing mothers aged 18-55 with children 5-12 years to women aged 18-55 without children. By examining whether in-person schooling has a stronger association with mothers' labor force attachment than non-mothers', we account for unobserved factors related to women's employment more generally. We use two independent linear probability models, one to compare mothers to fathers and another to compare mothers to non-mothers. Each model includes state-level fixed effects, individuallevel controls, as well the average daily rate of COVID-19 infections at the state-month level. We derive differences in labor force attachment between mothers and fathers and mothers and non-mothers with interaction terms between motherhood status and the weighted percentage of in-person school days offered by state.

Comparing mothers to fathers, Figure 5 shows that greater availability of in-person schooling was associated with a reduction in the gender gap in parents' labor force participation. This was driven through the association of in-person schooling and mothers', 
but not fathers', employment. An increase of 1 day of in-person schooling is associated with nearly a 1 percentage point increase in mothers' labor force participation relative to fathers $(\mathrm{p}<.05)$. Comparing mothers to women without children, Figure 6 shows a similar relationship: in-person schooling had a stronger relationship to mothers' labor force attachment. The effect size is about half of what was observed in comparing mothers to fathers, but remains significant $(\mathrm{p}<.05)$. Our results indicate that mothers' labor force attachment was stronger where in-person schooling was more prevalent.

\section{CONCLUSION}

Elementary school operating status varied across states and districts in fall 2020. About $56 \%$ of school districts operated in person, $25 \%$ of districts operated remotely, and $20 \%$ were hybrid. Despite most districts adopting in-person instruction, these schools served only $38 \%$ of elementary school students, compared to remote schools that served $45 \%$. Remote learning was the modal instructional form for schools with a larger share of Hispanic students, whereas in-person learning was most common for school districts where White students were overrepresented. School districts with a larger share of Black students were more evenly split between in-person and remote learning. These racial disparities persisted across geographic location (urban, suburban, rural) and COVID-19 prevalence. Importantly, these disparities represent inequities in options offered by school districts, rather than differences in parental uptake.

We show remote learning is negatively, but in-person education positively, associated with maternal employment during the pandemic. For each additional day of in-person schooling, we show between a half and one percentage point narrowing of the gap in maternal labor force participation relative to non-mothers and fathers, respectively. These associations remain significant net of state-level infection rates. ESOS data provides state and 
federal governments, policymakers, and advocacy groups with robust evidence to aid decision-making on school operations going forward. These data are also critical to support plans to address long-term implications for students who have experienced less in-person learning, as well as reentry support for mothers who have scaled back on employment in the absence of in-person instruction and care. 


\section{REFERENCES}

Bauer, L. (2021). Mothers are being left behind in the economic recovery from COVID-19. Brookings. May 6. https://www.brookings.edu/blog/up-front/2021/05/06/mothers-arebeing-left-behind-in-the-economic-recovery-from-covid-19/

Centers for Disease Control and Prevention. (2021). Operational Strategy for K-12 Schools through Phased Prevention. https://www.cdc.gov/coronavirus/2019ncov/community/schools-childcare/operation-strategy.html

Cowan, J. (2020). Newsom Order Would Keep Most California Schools Online. New York Times. https://www.nytimes.com/2020/07/17/us/california-schools-reopeningnewsom.html

Demillo, A. (2020). Arkansas: Schools must be open 5 days a week despite virus. The Associated Press. https://apnews.com/article/virus-outbreak-arkansasfc9d292679c2619ff0c331703b9f76c4

Dorn, E., Panier, F., Probst, N., \& Sarakatsannis, J. (2020). Back to school: A framework for remote and hybrid learning amid COVID-19. McKinsey \& Company. https://www.mckinsey.com/industries/public-and-social-sector/our-insights/back-toschool-a-framework-for-remote-and-hybrid-learning-amid-covid-19

Dong, E., Du, H, \& Gardner, L. (2020). An interactive web-based dashboard to track COVID-19 in real time. The Lancet. 20: 533-534.

Flood, Sarah, Miriam King, Renae Rodgers, Steven Ruggles and J. Robert Warren. Integrated Public Use Microdata Series, Current Population Survey: Version 8.0 [dataset]. Minneapolis, MN: IPUMS, 2020. https://doi.org/10.18128/D030.V8.0

Fraser, J., Stucka, M., Bloch, E., Fradette, R., \& Brugal, S. (2020). Florida schools reopened en masse, but a surge in coronavirus didn't follow, a USA TODAY analysis finds. USA Today. https://www.usatoday.com/story/news/investigations/2020/09/28/florida-schoolsreopened-en-mass-feared-covid-surge-hasn't-followed/3557417001/

Goldstein, A. (2020). State issues metrics-based guidance schools can consider for reopening. Pittsburgh Post-Gazette. https://www.post-gazette.com/news/education/2020/08/10/pareopen-schools-guidelines/stories/202008100089

Landivar, L. C., Ruppanner, L., Scarborough, W. J., \& Collins, C. (2020). Early Signs Indicate That COVID-19 Is Exacerbating Gender Inequality in the Labor Force. Socius. https://doi.org/10.1177/2378023120947997.

Lynch, M. (2016). Understanding Federal Funding Part I: 3 Types of School Funding. The Edvocate. https://www.theedadvocate.org/understanding-federal-funding-part-3-typesschool-funding/

McElrath, K. (2020). Nearly 93\% of Households With School-Age Children Report Some Form of Distance Learning During COVID-19. United States Census Bureau. https://www.census.gov/library/stories/2020/08/schooling-during-the-covid-19pandemic.html 
Morgan, I., \& Amerikaner, A. (2018). Funding Gaps: An Analysis of School Funding Equity Across the U.S. and Within Each State. Education Trust.

https://files.eric.ed.gov/fulltext/ED587198.pdf

Oregon Health Authority. (2020). Ready Schools, Safe Learners: Community COVID-19 Metrics.

https://www.oregon.gov/oha/PH/DISEASESCONDITIONS/DISEASESAZ/Emerging\%20 Respitory\%20Infections/Ready-Schools-Safe-Learners-Community-COVID-19Metrics.pdf

Petts, R., Carlson, D., \& Pepin, J. (2020). A gendered pandemic: Childcare, homeschooling, and parents' employment during COVID-19. SocArXiv. https://doi.org/10.31235/osf.io/gwkzx.

Thompson, C. (2021). Schools plan for potential of remote learning into the fall. ABC News. https://abcnews.go.com/Health/wireStory/schools-plan-potential-remote-learning-fall75752218

U.S. Department of Education. (2018). 10 Facts About K-12 Education Funding. https://www.ed.gov/about/overview/fed/10facts/index.html 
TABLE

Table 1. Reopening Status by District Characteristics

\begin{tabular}{lrrr}
\hline & In- & \\
& Person & Hybrid & Remote \\
\hline Share of all Districts & $55.7 \%$ & $19.7 \%$ & $24.6 \%$ \\
Share of all Students & $38.2 \%$ & $17.1 \%$ & $44.8 \%$ \\
Average Elementary Student Population & 1,818 & 2,310 & 4,849 \\
By Locale Setting & & \\
$\quad$ City & $30.9 \%$ & $15.1 \%$ & $54.2 \%$ \\
$\quad$ Suburb & $32.9 \%$ & $31.0 \%$ & $36.2 \%$ \\
$\quad$ Rural & $69.6 \%$ & $14.9 \%$ & $15.5 \%$ \\
Share of Children in Poverty & $16.1 \%$ & $13.3 \%$ & $18.2 \%$ \\
Average Cumulative COVID-19 Cases Per 100k Residents & 1,869 & 1,747 & 2,022 \\
$\quad$ as of September 30, 2020 & & & \\
District Racial Composition & & & \\
$\quad 25 \%+$ Black Students & $41.5 \%$ & $20.2 \%$ & $38.4 \%$ \\
25\%+ Hispanic Students & $37.5 \%$ & $12.4 \%$ & $50.1 \%$ \\
$75 \%+$ White Students & $68.2 \%$ & $21.1 \%$ & $10.7 \%$ \\
\hline
\end{tabular}

Note: Rates of COVID-19 derived from Johns Hopkins University Novel Coronavirus Visual Dashboard (Dong, Du, and Gardner 2020) county-level reports. All counties overlapping district boundaries included in district-level rates of COVID-19. District locale defined according to NCES classifications. 


\section{FIGURES}

Figure 1. Elementary School Operating Status, September 2020, by State

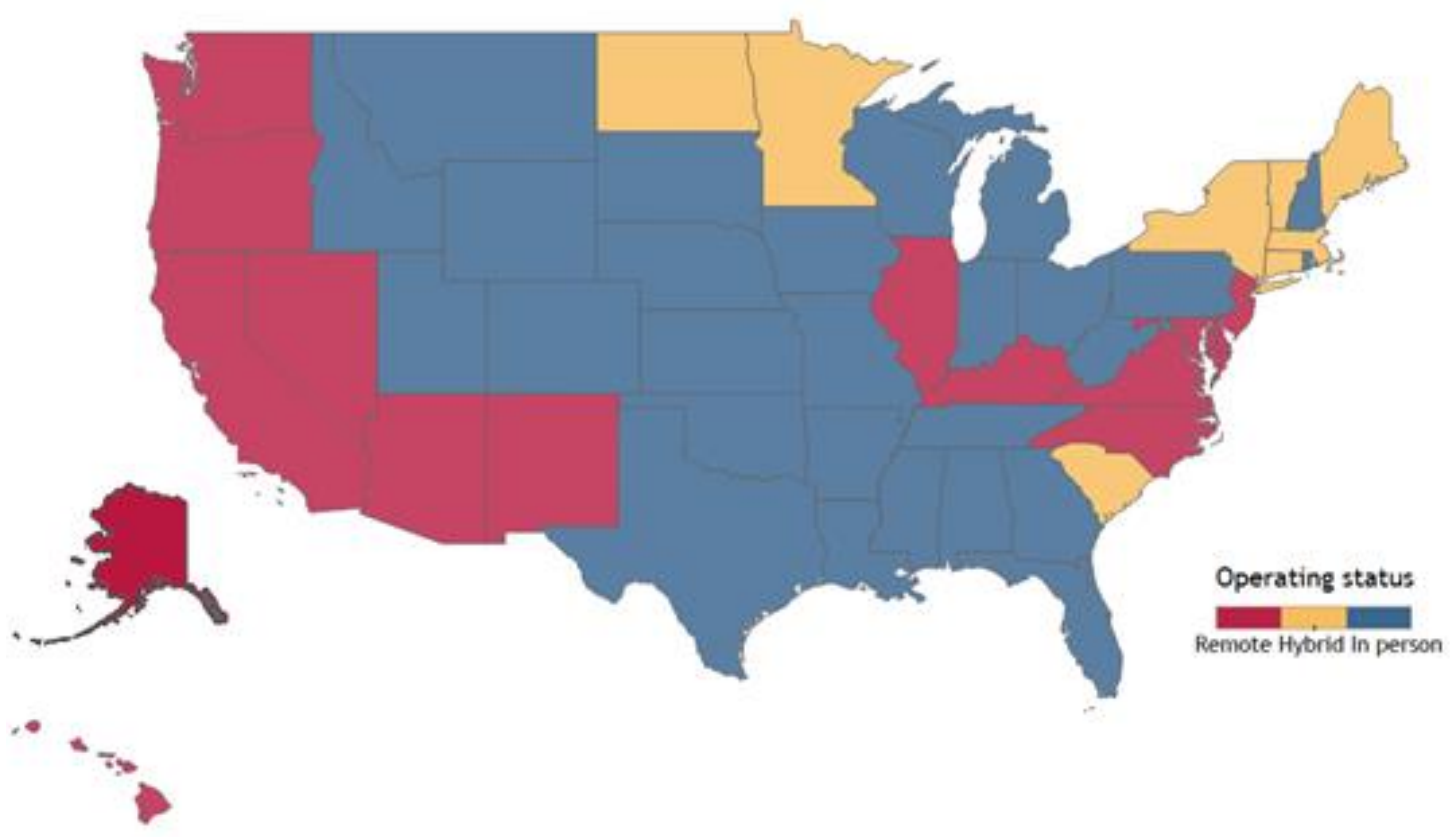

Source: Elementary School Operating Status, wave 1

Figure 2. Elementary School Operating Status, September 2020, by School District

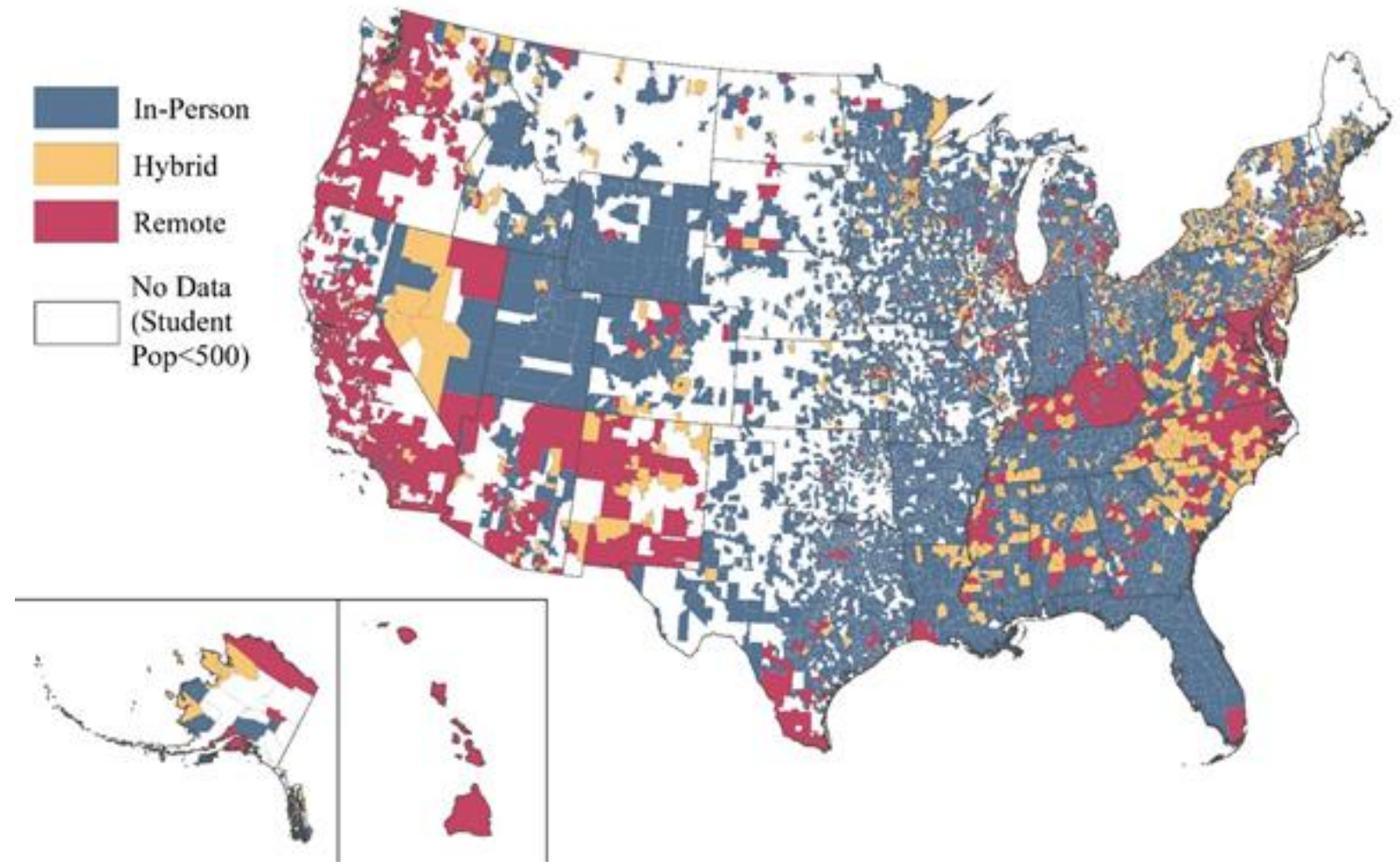

Source: Elementary School Operating Status, wave 1 
Figure 3. Share of School Districts Operating in In-person, Hybrid, or Remote Status by Race and Ethnicity of Student Population, September 2020

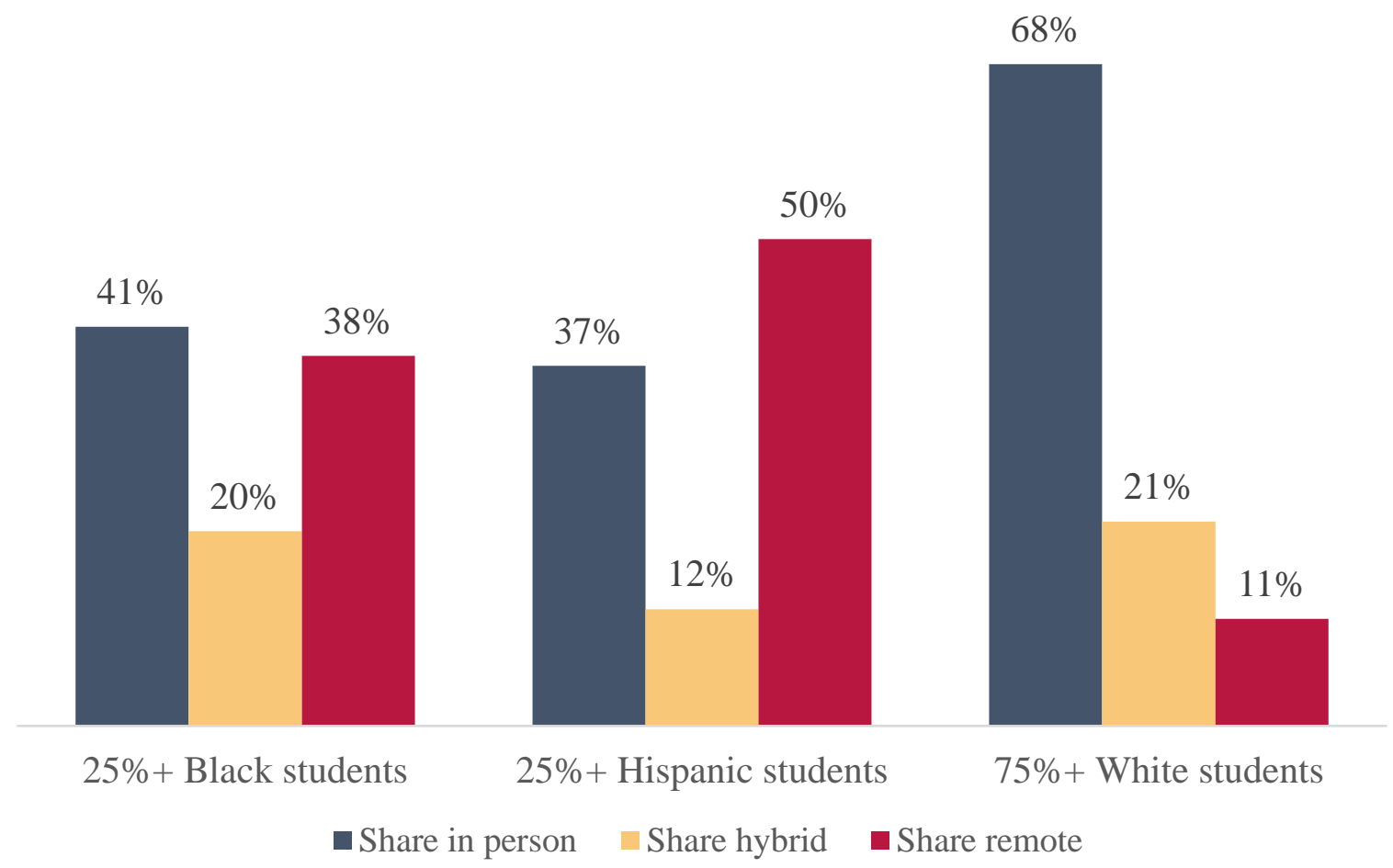

Note. School districts were classified as having a large share of Black or Hispanic students if Black or Hispanic students were at least $25 \%$ of the school district student population. White students were overrepresented if they were at least $75 \%$ of the school district student population.

Source: Elementary School Operating Status, wave 1 
Figure 4. Share of School Districts Operating in In-person, Hybrid, or Remote Status by Race and Ethnicity of Student Population, September 2020, Across Urban, Suburban, and Rural Locale
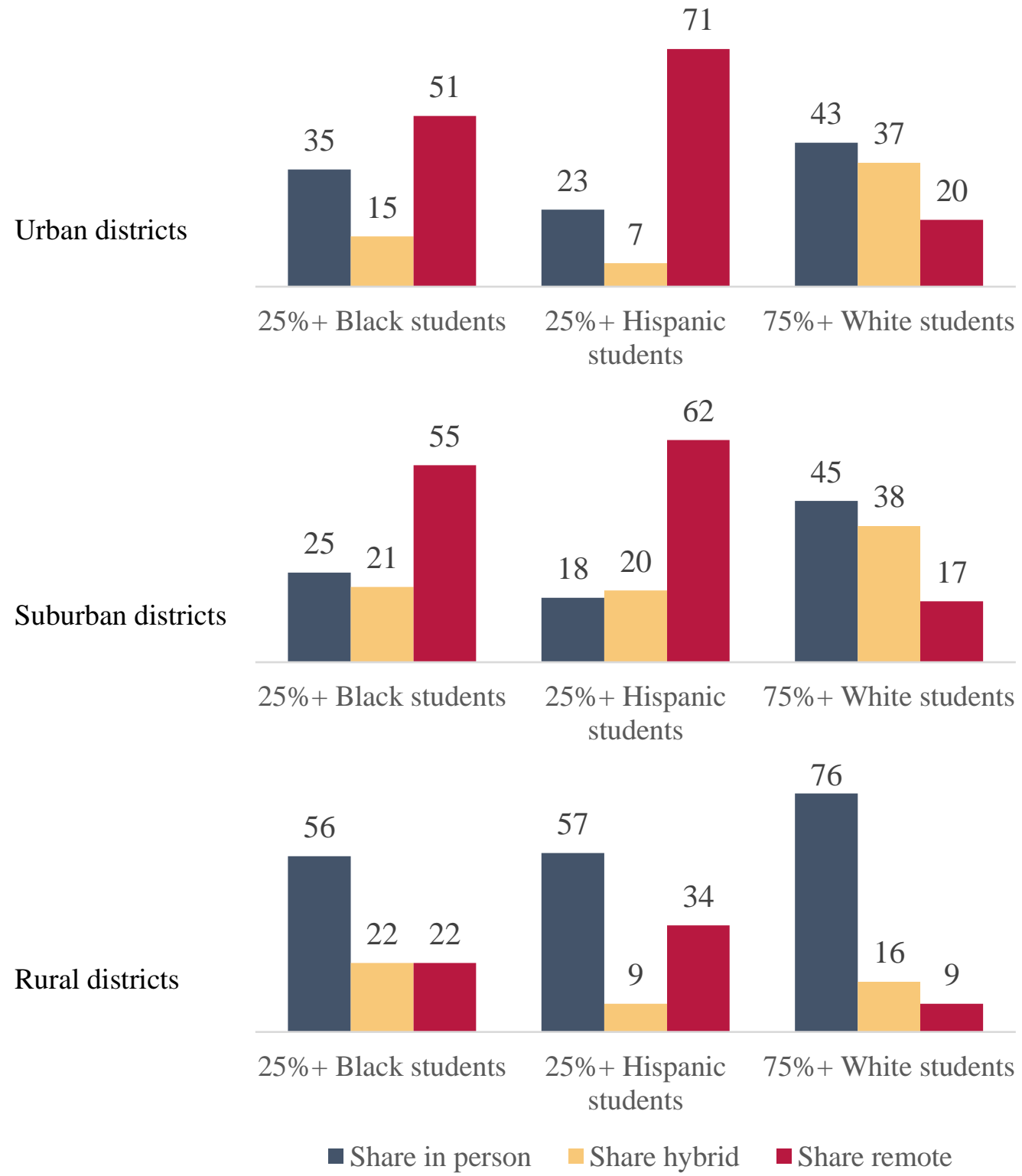

Note. School district geographic locale information is obtained from the National Center for Education Statistics, Elementary/Secondary Information System. Urban districts: city large, city midsize, city small; Suburban districts: suburban large, suburban midsize, suburban small; Rural districts: town fringe, town distant, town remote, rural fringe, rural distant, rural remote.

Source: Elementary School Operating Status, wave 1; National Center for Education Statistics. 
Figure 5. Gender Gap in Parents' Probability of Labor Force Participation by Average Share of Time in In-Person Schooling

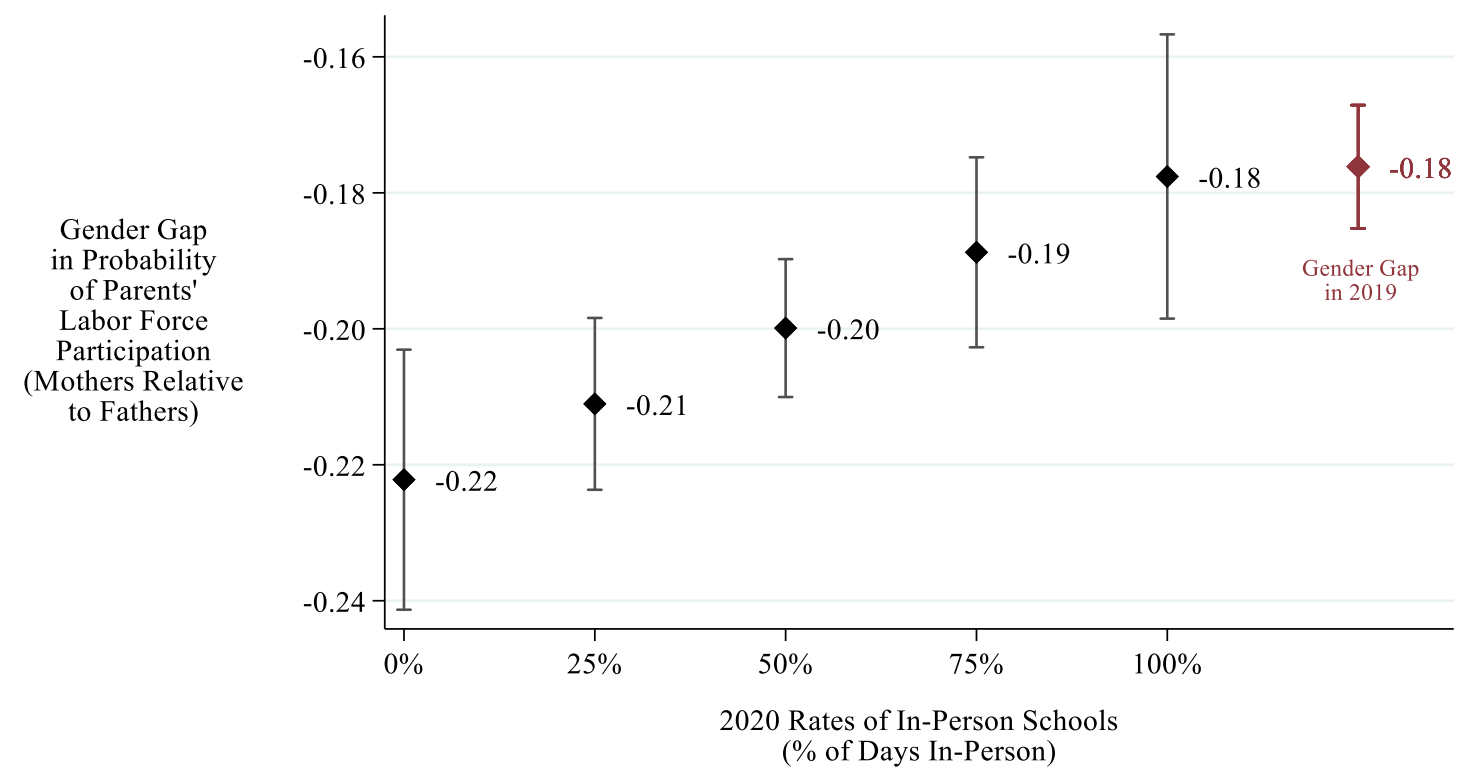

Note. Linear probability models with fixed effects for state and year to account for unobserved state characteristics and overall labor force shifts between 2019 and 2020. Results derived from an interaction between state-level percentage of in-person school days and gender. Controls include race, age, marital status, education, and state-level average daily cases of COVID-19 per 100,000 residents. Sample restricted to parents with youngest child aged 5-12 surveyed during fall 2019 and 2020. $n=50,864$. 
Figure 6. Motherhood Gap in Women's Probability of Labor Force Participation by Average Share of Time in In-Person Schooling

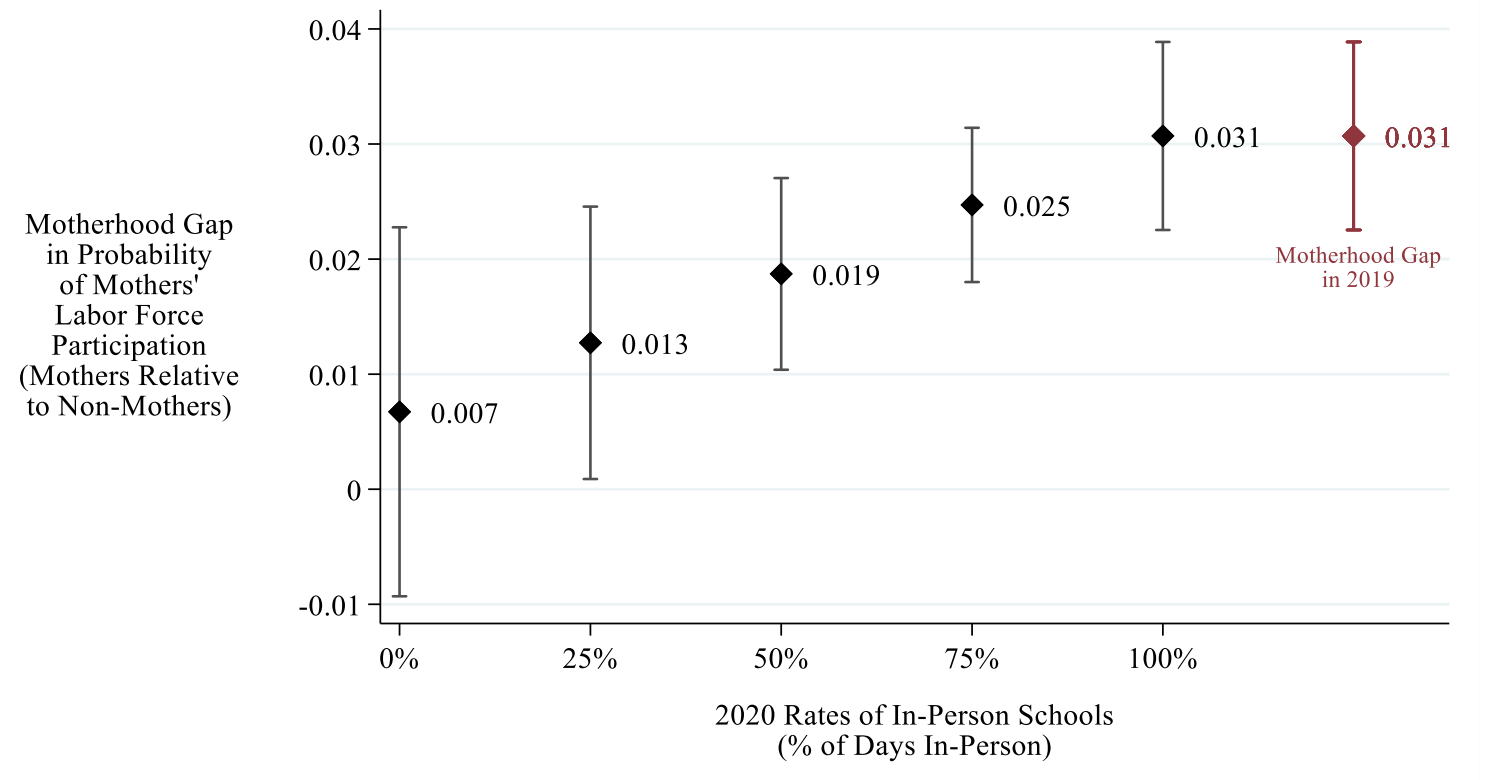

Note. Linear probability models with fixed effects for state and year to account for unobserved state characteristics and overall labor force shifts between 2019 and 2020. Results derived from an interaction between state-level percentage of in-person school days and motherhood status. Controls include race, age, marital status, education, and state-level average daily cases of COVID-19 per 100,000 residents. Sample restricted to mothers with at least one child aged 5-12 and non-mothers surveyed during fall 2019 and 2020. $\mathrm{n}=108,540$. 


\section{APPENDIX}

Table A1. Characteristics of Districts in ESOS Compared to Districts Excluded from ESOS

\begin{tabular}{lrr}
\hline & Excluded from \\
& $9,195(72 \%)$ & $3,562(28 \%)$ \\
\hline Number of Districts & $24,354,543(98 \%)$ & $493,062(2 \%)$ \\
Total Elementary School Students & $11.5 \%$ & \\
District Racial Composition & $20.8 \%$ & $1.9 \%$ \\
25\%+ Black Students & $51.8 \%$ & $67.6 \%$ \\
$25 \%+$ Hispanic Students & & \\
$75 \%+$ White Students & $7.6 \%$ & $0.2 \%$ \\
By Locale Setting & $29.7 \%$ & $4.8 \%$ \\
City & $62.7 \%$ & $95.0 \%$ \\
Suburb & 1,882 & 1,673 \\
$\quad$ Rural & & \\
Average Cumulative COVID-19 Cases Per & & \\
100k Residents as of September 30, 2020 & & \\
Note: Only public school districts with elementary instruction included. ESOS restricted to \\
districts with at least 500 students. Rates of COVID-19 derived from Johns Hopkins \\
University Novel Coronavirus Visual Dashboard (Dong, Du, and Gardner 2020) county-level \\
reports. All counties overlapping district boundaries included in district-level rates of COVID- \\
19. District locale defined according to NCES classifications.
\end{tabular}


Figure A1. Share of School Districts Operating in In-person, Hybrid, or Remote Status by Race and Ethnicity of Student Population, September 2020, Across Low, Moderate, and High Rates of COVID-19 Infection

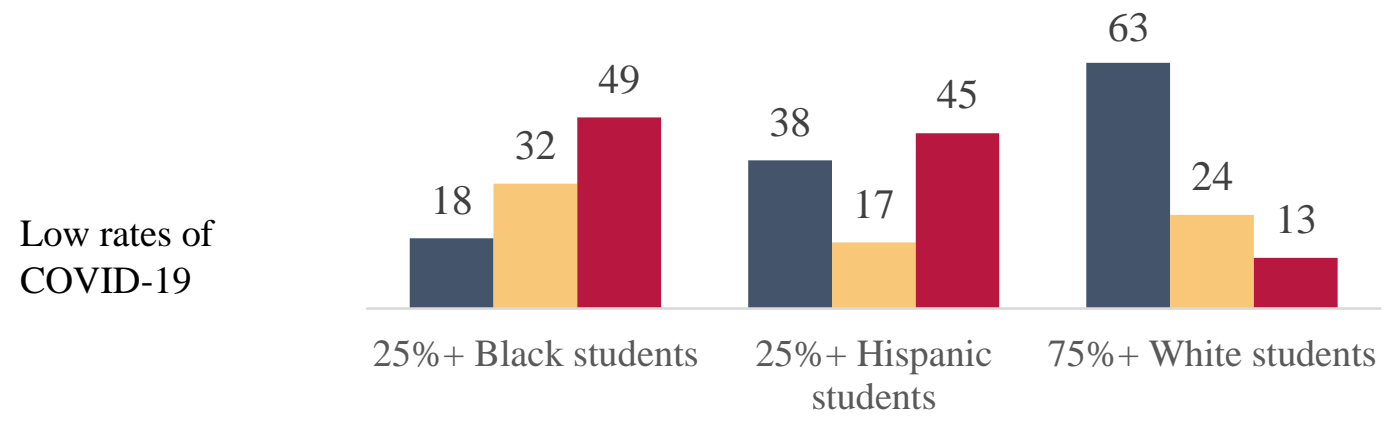

Mid rates of

COVID-19

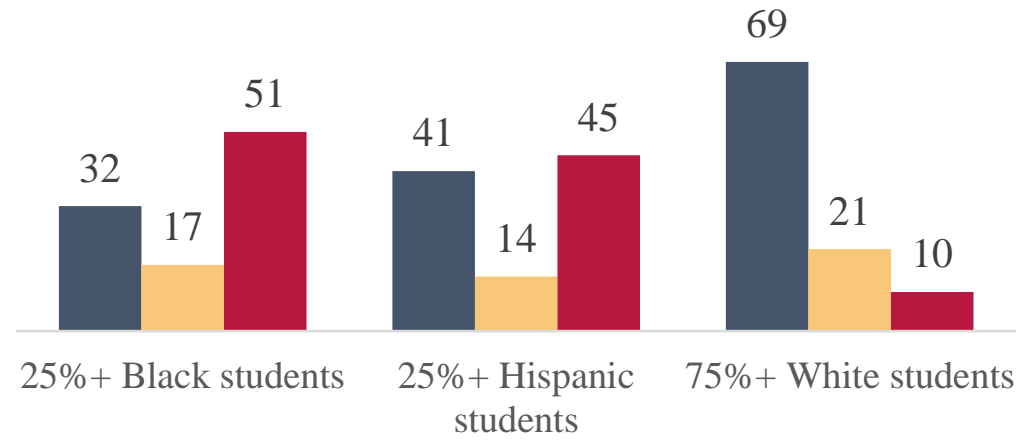

High rates of

COVID-19

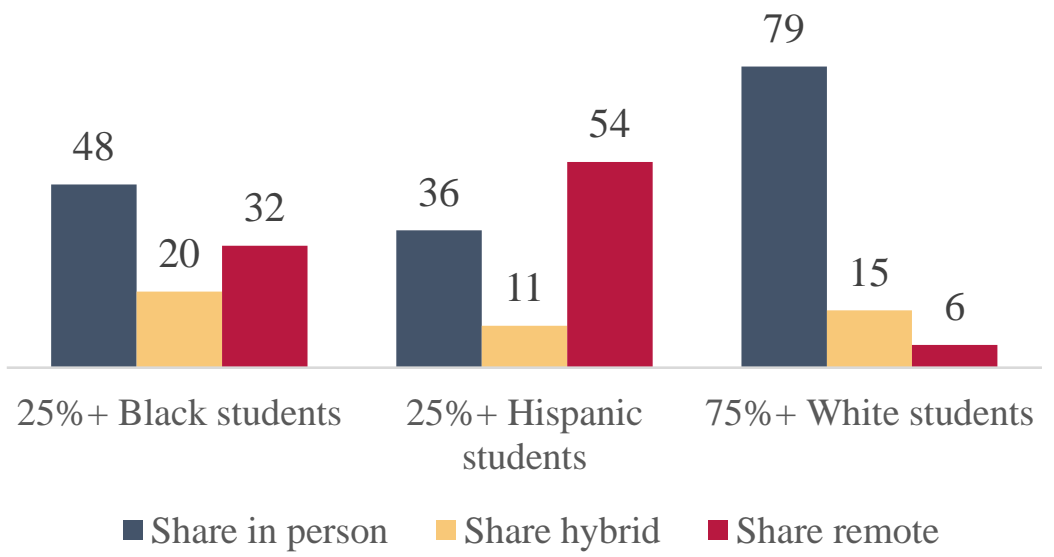

Note. Rates of COVID-19 classified as low if fewer than 1,265 cases per 100,000 residents (33rd percentile); moderate if between 1,265 and 2,181 per 100,000 residents (33rd and 66th percentile), and high if above 2,181 per 100,000 residents.

Source: Elementary School Operating Status, wave 1. Rates of COVD-19 derived from the CDC (2021) for September, 2021. 